\title{
Análise espacial das infrações à Norma Brasileira de Comercialização de Alimentos Infantis, bicos, chupetas e mamadeiras na cidade de Belém - Pará, Brasil
}

Spatial analysis of infringements of the Brazilian Standard on The Marketing of Children's Foods, tips, pacifiers and bottles in the city of Belém - Pará, Brazil

Análisis espacial de infracciones a la Norma Brasileña de Comercialización de Alimentos, puntas, chupones y botellas infantiles en la ciudad de Belém - Pará, Brasil

Túlio Gonçalves Gomes ORCID: https://orcid.org/0000-0002-9992-3205 Universidade Federal do Pará, Brasil

E-mail: tulio-gomes@hotmail.com

Naiza Nayla Bandeira de Sá

ORCID: https://orcid.org/0000-0002-1267-1624 Universidade Federal do Pará, Brasil E-mail: naizasa@ufpa.br

Daniela Lopes Gomes

ORCID: https://orcid.org/0000-0002-0092-3396 Universidade Federal do Pará, Brasil E-mail: danielagomes@ufpa.br

Juliana Mara Flores Bicalho

ORCID: https://orcid.org/0000-0003-1445-8234 Universidade Federal de São João Del Rei, Brasil E-mail: jmfbicalho@gmail.com

Gustavo Henrique Oliveira

ORCID: https://orcid.org/0000-0003-2779-2549

Centro Universitário Una, Brasil

E-mail: contato.gholiveira@gmail.com

Cristiano Siqueira Boccolini

ORCID: https://orcid.org/0000-0002-4804-5641 Fundação Oswaldo Cruz, Brasil

E-mail: cristianoboccolini@gmail.com

\begin{abstract}
Resumo
O aleitamento materno, exclusivo até seis meses de idade e associado à alimentação complementar adequada de seis meses até dois anos ou mais, é a prática alimentar ideal, capaz de diminuir mortalidade infantil, promover crescimento e desenvolvimento satisfatórios e garantir diversos fatores de proteção para mães e filhos. No entanto, o comércio de alimentos substitutos do leite materno, impulsionado por estratégias mercadológicas vem sendo apontado como um dos principais fatores associados à baixa prevalência de aleitamento materno no mundo. Como resposta, a Organização Mundial da Saúde publicou, em 1981, o Código Internacional de Comercialização de Alimentos Substitutos do Leite Materno. No Brasil, o marco legal mais importante em defesa da amamentação é a Norma Brasileira de Comercialização de Alimentos para Lactentes e Crianças de Primeira Infância, Bicos, Chupetas e Mamadeiras (NBCAL). O objetivo desse trabalho foi identificar as infrações à NBCAL, encontradas em farmácias do município de Belém. Além de classificar o tipo de infração, quantidade de ocorrência nas farmácias e georreferenciar os locais para análise das suas características. Foram avaliadas 145 farmácias em 33 bairros. Em 72\% dos estabelecimentos foi evidenciado algum tipo de infração: 74 farmácias ofereciam desconto, 75 infringiram as regras de exposição espacial e 48 cometeram ambos. A elevada taxa de infrações encontrada reforça que, em Belém (PA), as políticas públicas para promoção do aleitamento materno devem, obrigatoriamente, incluir o aumento da fiscalização dos estabelecimentos comerciais quanto ao cumprimento da NBCAL. Palavras-chave: Aleitamento materno; Comercialização de produtos; Nutrição da criança; Substitutos do leite humano.
\end{abstract}

\footnotetext{
Abstract

Exclusive breastfeeding up to six months of age and associated with adequate complementary feeding from six months to two years or more is the ideal feeding practice, capable of reducing infant mortality, promoting satisfactory growth and development and ensuring several protective factors for mothers and sons. However, the trade in food substitutes for breast milk, driven by marketing strategies, has been identified as one of the main factors associated with the low prevalence of breastfeeding in the world. In response, the World Health Organization published, in 1981, the International Code of Marketing of Food Substitutes for Breast Milk. In Brazil, the most important legal framework in defense of breastfeeding is the Brazilian Norm for the Marketing of Food for Infants and Early Childhood Children,
} 
nipples, pacifiers and baby bottles (NBCAL). The objective of this study was to identify NBCAL infractions found in pharmacies in the city of Belém. In addition to classifying the type of infraction, number of occurrences in pharmacies and georeferencing the locations for analysis of their characteristics. 145 pharmacies in 33 districts were evaluated. In $72 \%$ of the establishments some type of infraction was evidenced: 74 pharmacies offered discounts, 75 infringed the rules of spatial exposure and 48 committed both. The high rate of infringements found reinforces that, in Belém (PA), public policies to promote breastfeeding must necessarily include increased inspection of commercial establishments regarding compliance with NBCAL.

Keywords: Breast feeding; Products commerce; Child nutrition; Breast-milk substitutes.

\section{Resumen}

La lactancia materna exclusiva hasta los seis meses de edad y asociada a una alimentación complementaria adecuada desde los seis meses hasta los dos años o más es la práctica de alimentación ideal, capaz de reducir la mortalidad infantil, promover un crecimiento y desarrollo satisfactorios y asegurar varios factores protectores para madres e hijos. Sin embargo, el comercio de sucedáneos de la leche materna, impulsado por estrategias de marketing, ha sido identificado como uno de los principales factores asociados a la baja prevalencia de la lactancia materna en el mundo. En respuesta, la Organización Mundial de la Salud publicó, en 1981, el Código Internacional de Comercialización de Sucedáneos de Alimentos para la Leche Materna. En Brasil, el marco legal más importante en defensa de la lactancia materna es la Norma Brasileña para la Comercialización de Alimentos para Lactantes y Primera Infancia, tetinas, chupetes y biberones (NBCAL). El objetivo de este estudio fue identificar las infracciones NBCAL encontradas en las farmacias de la ciudad de Belém, además de clasificar el tipo de infracción, número de ocurrencias en las farmacias y georreferenciar las ubicaciones para el análisis de sus características. Se evaluaron 145 farmacias en 33 distritos. En el 72\% de los establecimientos se evidenció algún tipo de infracción: 74 farmacias ofrecieron descuentos, 75 infringieron las reglas de exposición espacial y 48 cometieron ambas. La alta tasa de infracciones encontradas refuerza que, en Belém (PA), las políticas públicas para promover la lactancia materna necesariamente deben incluir una mayor inspección de los establecimientos comerciales en cuanto al cumplimiento de la NBCAL.

Palabras clave: Lactancia materna; Comercialización de productos; Nutrición del niño; Sustitutos de la leche humana.

\section{Introdução}

O aleitamento materno é a prática alimentar ideal para o crescimento e desenvolvimento infantil nos primeiros seis meses de vida, afetando diretamente a sobrevivência do recém-nascido e promovendo diversos fatores de proteção para ele e sua mãe. Sua continuidade até dois anos ou mais, aliada à alimentação complementar adequada (dos seis meses em diante), é decisiva para o bom estado nutricional e desenvolvimento saudável de infantes (World Health Organization [WHO], 2008).

Além de ser de baixo custo, a prática alimentar da amamentação traz benefícios para a nutriz, como diminuir o risco de hemorragia pós-parto, câncer de mama e fortalecer o vínculo entre a mãe e o bebê, podendo ainda favorecer a perda de peso pósgestacional (Gradim et al., 2011). Para o bebê, os benefícios concretos são: a melhora na imunidade, diminuição do risco de desenvolver obesidade nos anos seguintes, proteção contra o desenvolvimento de diabetes tipo 2 e outras Doenças Crônicas Não Transmissíveis (DCNT) e desenvolvimento adequado do sistema estomatognático (Braga et al., 2020; Victora et al., 2016).

No Brasil, a prevalência de aleitamento materno exclusivo (AME) é de aproximadamente 41\%, segundo United Nations Children's Fund (UNICEF, 2016). No mundo, essa taxa variou entre 26 e 82\%, como apontam dados de metanálise executada por Victora et al. (2016), que avaliou diversos aspectos ligados ao aleitamento materno em 153 países.

A literatura atual, aponta os mitos sociais, a inserção de bicos artificiais como os interferentes mais citados como interferentes do aleitamento materno exclusivo (Barbosa et al., 2020).

A Organização Mundial da Saúde (OMS) pretende que ocorra um aumento da prática de AME até 2025, através da expansão dos Hospitais Amigos da Criança, apoio à amamentação, empoderamento feminino, treinamentos, capacitações e redução da comercialização agressiva de substitutos do leite materno pela indústria alimentícia (WHO, 2014).

Uma vez que a indústria de alimentos transformou-se em um sistema heterogêneo, especializado, integrado a sistemas de produção agroindustriais de alta produção (como de leite, cereais, etc.), sua atuação como ditadora de comportamentos alimentares tornou o alimento como mercadoria [sujeito a práticas de capitalismo], por isso analisa-se a existência da implementação de um sistema de produção, distribuição e consumo desigual e injusto que afeta a saúde pública em diversos níveis (Machado et al., 2016). 
No Brasil, um dos marcos na defesa da amamentação infantil, é, sem dúvida, a criação da Norma Brasileira de Comercialização de Alimentos para Lactentes e Crianças de Primeira Infância, Bicos, Chupetas e Mamadeiras (NBCAL), baseada no Código Internacional de Comercialização de Substitutos do Leite Materno. De acordo com esta legislação, leites, cereais, mamadeiras, chupetas e bicos, devem seguir normas de exposição e venda em farmácias e supermercados, visando à diminuição da comercialização agressiva destes artigos e a indução à compra de produtos desta classe (International Baby Food Action Network [IBFAN], 2007).

A NBCAL não regulamenta apenas a comercialização de alimentos que podem ser ofertados para primeira e segunda infâncias (considerando a primeira infância como o período do nascimento aos três anos, e a segunda infância, dos três aos seis anos de idade), mas ainda uma série de produtos que pode ter impacto negativo na amamentação, causar piora do estado nutricional, estimular o desmame precoce da criança e ainda levar a deformidades na cavidade oral (Pereira-Santos et al., 2017; Rochelle et al., 2010).

Existem poucos estudos que avaliam o cumprimento da norma ao longo dos anos no Brasil, mesmo assim, é possível ter um vislumbre de como as práticas da indústria e comércio ainda necessitam de adequações para que de fato as leis protejam mães e bebês das práticas abusivas de comércio. Além disso, considerando as dimensões continentais do Brasil e suas pluralidades são necessárias análises bem estruturadas e planejadas, realizadas com base em conhecimentos de nuances culturais e sociais.

Este trabalho possui lócus a cidade de Belém- Pará (PA). Embora existam outros monitoramentos na área de amamentação e alimentação infantil, estudos baseados na NBCAL ambientados na capital paraense são praticamente inexistentes. A Região Norte (RN) é singular em seus processos históricos de urbanização, possui índices de desenvolvimento socioeconômico baixos, as singularidades climáticas e físicas predominantes, a força do traço cultural intensamente presente e os conflitos pela terra (Santana \& Holanda, 2012) demarcam diferenças notáveis para uma análise mais apurada dos resultados.

O objetivo desse trabalho foi identificar as infrações à NBCAL, encontradas em farmácias do município de Belém. Além disso, buscou-se caracterizar as infrações e classificar segundo o seu tipo e quantidade de ocorrência nas farmácias e georreferenciar os locais de coleta, para analisar suas particularidades sob a ótica de suas especificidades: localização e espalhamento de infrações.

\section{Materiais e Métodos}

O presente estudo integra um estudo multicêntrico denominado: "Estudo multicêntrico de avaliação do cumprimento da Norma Brasileira de Comercialização de Alimentos para Lactentes e Crianças de Primeira Infância, Bicos, Chupetas e Mamadeiras (Multi-NBCAL)". Trata-se de um estudo transversal, epidemiológico, que objetivou a avaliação do cumprimento da NBCAL em estabelecimentos comerciais e hospitais com maternidade em seis cidades do Brasil: de Rio de Janeiro (RJ), São Paulo (SP), Brasília (DF), João Pessoa (PB), Ouro Preto (MG), Florianópolis (SC) e Belém (PA). Esta pesquisa foi aprovada pela Comissão Nacional de Ética em Pesquisa, sob o parecer n ${ }^{\circ}$ 2.912.729. O estudo foi conduzido por profissionais de saúde, treinados e qualificados para tal, nas cidades a abrangência do estudo possibilita a comparação entre cidades com diferentes IDH.

Para este trabalho foram considerados apenas os dados referentes ao município de Belém. Os pesquisadores foram escolhidos entre profissionais de nutrição, treinados e capacitados para pesquisa de campo no ano de 2018. O monitoramento da cidade de Belém é parte do projeto inicial "Multi NBCAL".

Os questionários utilizados foram baseados nos métodos analíticos da IBFAN (2008) e Instituto Brasileiro de Defesa do Consumidor (IDEC, 2015) para observância da Lei 11.265/06, e utilizados em pesquisa de campo no ano de 2017.

O estudo intitulado "Estudo multicêntrico de avaliação do cumprimento da Norma Brasileira de Comercialização de Alimentos para Lactentes e Crianças de Primeira Infância, Bicos, Chupetas e Mamadeiras (Multi-NBCAL)" realizou-se em três etapas: a) Elaboração e validação (estudo-teste) de questionário de avaliação do cumprimento da NBCAL em Estabelecimentos Comerciais e Hospitais com Maternidade - estudo teste com a amostra de 32 estabelecimentos na Zona Sul do Rio de Janeiro; b) 
Inquérito epidemiológico multicêntrico para avaliar o cumprimento da NBCAL em Estabelecimentos Comerciais e Hospitais com Maternidade; c) Estudo qualitativo para avaliar a percepção das mães sobre os produtos abrangidos pela NBCAL e a influência do marketing da indústria de alimentos e produtos abrangidos pela NBCAL nas escolhas relacionadas à alimentação dos seus filhos durante os três primeiros anos de vida; além da entrevista com profissionais de vigilância sanitária quanto à fiscalização e reforço da NBCAL.

Inicialmente, em meados de 2018, foram obtidos os nomes e endereços de todos os estabelecimentos comerciais que fariam parte da rota de pesquisa através de busca ativa utilizando a internet e os dados da Vigilância Sanitária do município (VISA). Um trajeto foi apresentado aos pesquisadores. Na coleta da cidade de Belém que ocorreu em novembro de 2018, foram contemplados os seguintes bairros: Agulha/ Icoaraci, Batista Campos, Bengui, Cabanagem, Campina, Castanheira, Cidade Velha, Comércio, Coqueiro, Cremação, Cruzeiro/ Icoaraci, Curió/Utinga, Fátima, Guamá, Icoaraci, Jurunas, Mangueirão, Marambaia, Marco, Marex, Nazaré, Parque verde, Pedreira, Reduto, Sacramenta, São Brás, Souza, Tapanã, Telégrafo, Terra Firme, Umarizal, Umarizal, Val-de-Cans.

Ao identificar o estabelecimento no qual iriam coletar os dados, os pesquisadores avaliaram o ambiente do estabelecimento, seguidos da identificação dos produtos comercializados, das promoções comerciais presentes, finalizando com o registro no formulário eletrônico das infrações observadas, não foi necessária a identificação pessoal do pesquisador, uma vez que se trata de espaço público, sem interação com pessoas - esse procedimento visa garantir que não sejam alteradas possíveis infrações após a identificação dos entrevistadores. A segunda parte da coleta consistiu no entrevistador se apresentar ao gerente, identificando-se e obtendo a assinatura do termo de consentimento livre e esclarecido (TCLE) procedendo com a entrevista. Para proceder no monitoramento, registro fotográfico e entrevista, utilizou-se o software Magpi+ ${ }^{\circledR}$.

\section{Resultados}

O mapeamento identificou três tipos de estabelecimentos na cidade de Belém: farmácias, supermercados e atacados/varejos. Em 33 bairros foram mapeados 200 estabelecimentos, dentre eles, 145 eram farmácias (72,5\%). As farmácias foram maioria das unidades pesquisadas, tal resultado não parte de um viés dos pesquisadores, mas sim, parte de uma proporção maior para os outros tipos de estabelecimentos incluídos no mapeamento da NBCAL. No período do inquérito, foi possível observar inclusive a concentração delas (farmácia) nos mesmos espaços. As infrações por bairro foram identificadas conforme expressa a Tabela 1. A coluna "Percentual com infrações" expressa a proporção de farmácias que apresentaram infrações para o total pesquisado em cada bairro. 
Research, Society and Development, v. 10, n. 17, e110101723878, 2021

(CC BY 4.0) | ISSN 2525-3409 | DOI: http://dx.doi.org/10.33448/rsd-v10i17.23878

Tabela 1. Infrações em farmácias por bairros de Belém - Pará, 2018.

\begin{tabular}{|c|c|c|c|c|}
\hline Bairro & Com infração & Sem infração & $\begin{array}{l}\text { Total de } \\
\text { farmácias }\end{array}$ & $\begin{array}{l}\text { Percentual com } \\
\text { infrações }(\%)\end{array}$ \\
\hline Agulha - Icoaraci & 1 & 2 & 3 & 33,3 \\
\hline Batista Campos & 7 & 3 & 10 & 70,0 \\
\hline Bengui & 1 & 0 & 1 & 100,0 \\
\hline Cabanagem & 0 & 2 & 2 & 0,0 \\
\hline Campina & 1 & 0 & 1 & 100,0 \\
\hline Castanheira & 1 & 1 & 2 & 50,0 \\
\hline Cidade velha & 1 & 0 & 1 & 100,0 \\
\hline Comercio & 1 & 2 & 3 & 33,3 \\
\hline Coqueiro & 1 & 0 & 1 & 100,0 \\
\hline Cremação & 3 & 2 & 5 & 60,0 \\
\hline Cruzeiro - Icoaraci & 2 & 1 & 3 & 66,7 \\
\hline Curió/Utinga & 0 & 1 & 1 & 0,0 \\
\hline Fatima & 2 & 0 & 2 & 100,0 \\
\hline Guama & 6 & 3 & 9 & 66,7 \\
\hline Icoaraci & 3 & 0 & 3 & 100,0 \\
\hline Jurunas & 1 & 0 & 1 & 100,0 \\
\hline Mangueirão & 1 & 2 & 3 & 33,3 \\
\hline Marambaia & 5 & 1 & 6 & 83,3 \\
\hline Marco & 17 & 2 & 19 & 89,5 \\
\hline Nazaré & 4 & 4 & 8 & 50,0 \\
\hline Parque Verde & 3 & 3 & 6 & 50,0 \\
\hline Pedreira & 10 & 2 & 12 & 83,3 \\
\hline Reduto & 6 & 2 & 8 & 75,0 \\
\hline Sacramenta & 3 & 4 & 7 & 42,9 \\
\hline São Brás & 5 & 1 & 6 & 83,3 \\
\hline Souza & 1 & 2 & 3 & 33,3 \\
\hline Tapanã & 1 & 0 & 1 & 100,0 \\
\hline Telégrafo & 3 & 2 & 5 & 60,0 \\
\hline Terra Firme & 2 & 1 & 3 & 66,7 \\
\hline Umarizal & 7 & 1 & 8 & 87,5 \\
\hline Val de Cães & 2 & 0 & 2 & 100,0 \\
\hline
\end{tabular}

Fonte: Autores (2020).

O Gráfico a seguir analisa a quantidade de infrações em bairros onde foram mapeadas mais de cinco farmácias. Marco e Umarizal foram os bairros que mais ocorreram infrações na proporção de locais avaliados para locais com infração, estes foram seguidos por São Brás, Marambaia e Pedreira. 
Figura 1. Percentual de infrações em farmácias em bairros com mais de 5 amostras em Belém - Pará, 2018.

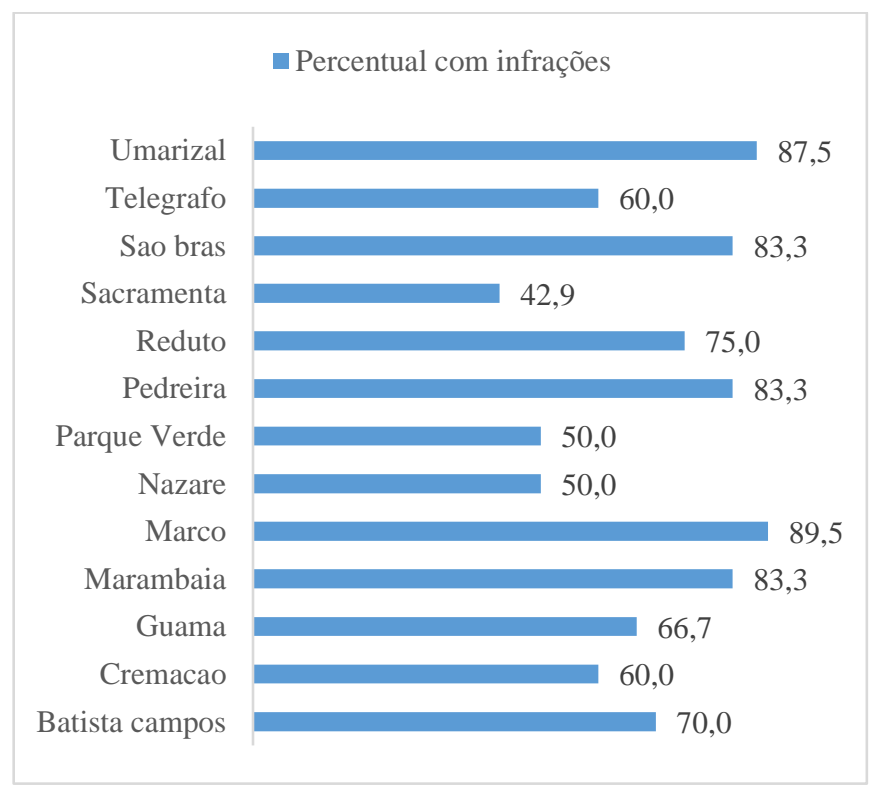

Fonte: Autores (2020).

As redes de farmácias estavam presentes em grande número nos locais pesquisados, do total pesquisado (145), apenas $13 \%$ não faziam parte de uma rede/franquia. De modo geral, a maioria das farmácias era de pequeno ou médio porte. Das farmácias que faziam parte de uma rede e não estavam no interior de supermercados, 70,5\% eram pequenas ou médias. Das farmácias analisadas na pesquisa é expressiva a diferença entre os que infringiram e os que não infringiram a norma (30\% não infringiram a norma, $70 \%$ infringiram)

Como é possível notar na Figura 2, os locais onde as infrações foram mais presentes são os bairros da região central da cidade, onde a maior parte das farmácias está concentrada e tradicionalmente onde se localizam os locais com maior renda per capta e/ou tem maior especulação imobiliária.

A maioria dos bairros de região não central foram os que apresentaram menos de cinco infrações por local (apresentados pela cor azul). Em verde e amarelo aparecem os locais que tiveram entre seis e 19 infrações, número que também expressa uma quantidade grande de infrações. Alguns locais da pesquisa, como shoppings e alguns cruzamentos, concentravam mais de um estabelecimento do tipo farmácia, de certa forma, essa configuração permite uma possibilidade de escolhas no mesmo espaço, onde se pode, sistematicamente, dizer que é provável que o consumidor esteja exposto não apenas às irregularidades de um dos locais, mas à soma deles, pois estão no mesmo espaço. Isso dificulta a possibilidade de uma escolha adequada.

No mapa da Figura 3, que exibe as infrações por tipo e diferenciando a presença de um ou mais estabelecimentos, os pontos em laranja representam a presença de infrações do tipo "desconto" e exposição especial. A dispersão e o agrupamento de pontos com infração e ausência delas estão semelhantes na representação gráfica. Os pontos com mais de um local tiveram quase totalmente a presença de ambos os tipos de infração mapeados. Um recorte nos núcleos de agrupamento de pontos (pesquisados) mais distantes do centro de Belém demonstra uma maior proporção de locais sem infração. Assim pode se dizer graficamente que a probabilidade de encontrar uma farmácia que não contenha infração (ou também menos infrações por local) é muito menor na região central que no recorte mais distante. Um dos motivos pode ser a densidade demográfica maior no recorte central, mas este paralelo também figura a desigualdade quanto ao cumprimento da NBCAL em cada núcleo. 
Research, Society and Development, v. 10, n. 17, e110101723878, 2021

(CC BY 4.0) | ISSN 2525-3409 | DOI: http://dx.doi.org/10.33448/rsd-v10i17.23878

Figura 2. Quantidade de infrações por área em Belém - Pará, 2018.

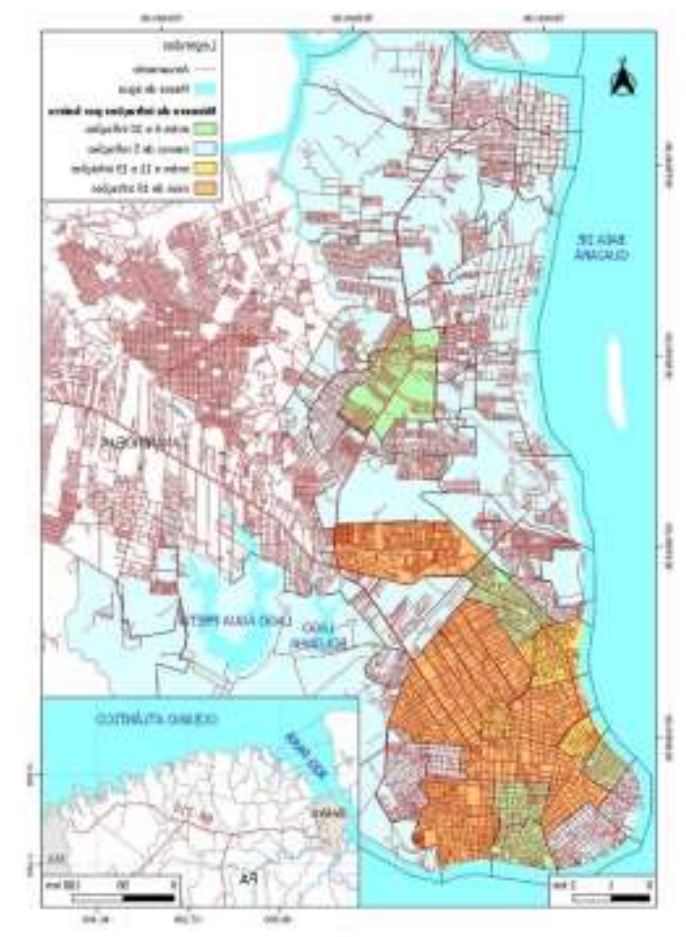

Fonte: Autores (2020). 
Figura 3 - Espalhamento dos pontos mapeados e tipo de infração em Belém - Pará, 2018.

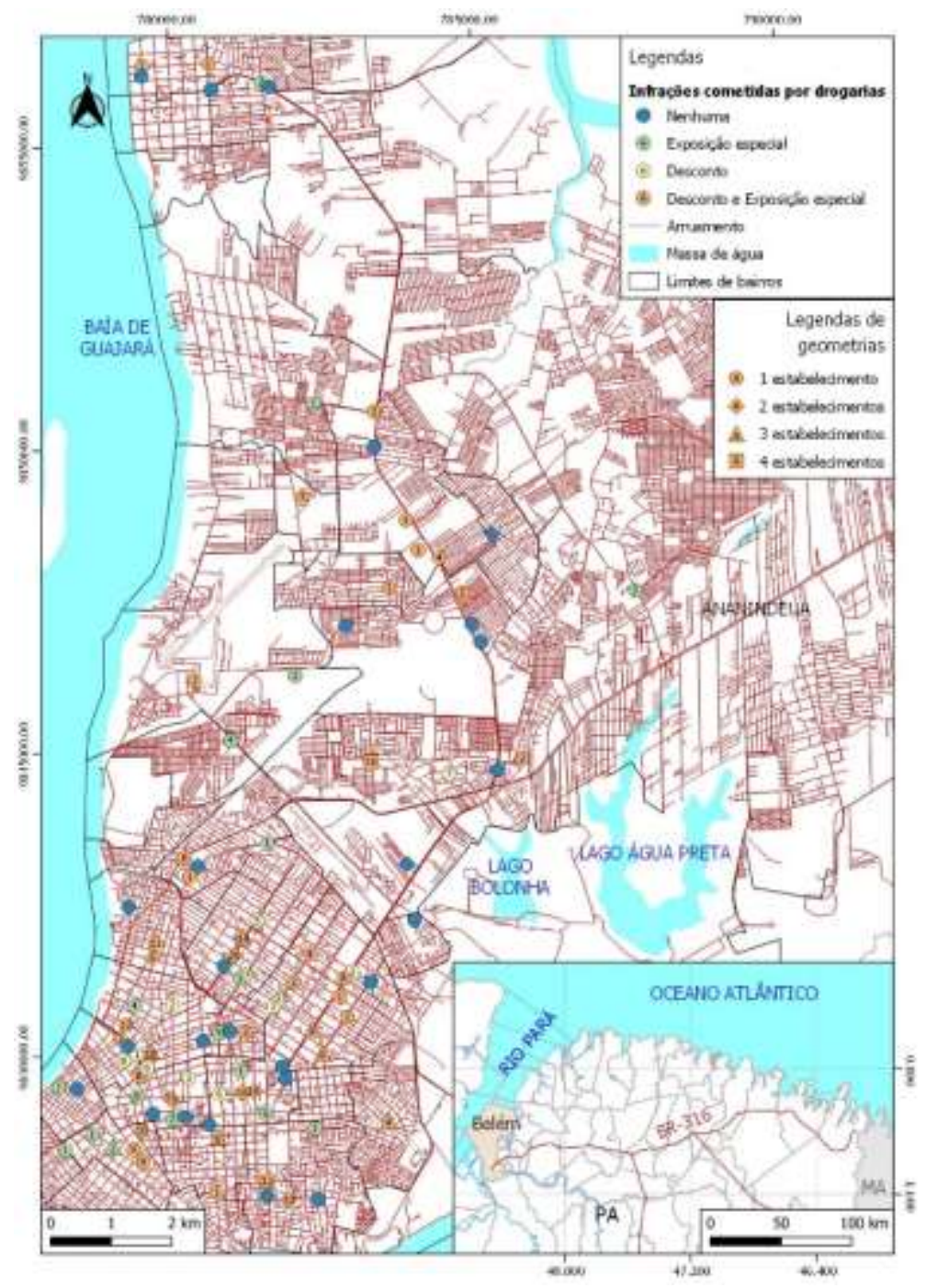

Fonte: Autores (2020).

Em duas avenidas importantes da cidade, Almirante Barroso e Pedro Miranda, que são de grande movimentação, por serem vias de acesso e ligação entre partes distintas da cidade e possuem uma concentração grande de estabelecimentos, se apresentam alguns pontos críticos. Na Avenida Pedro Miranda, temos no espaço de seis quarteirões, nove farmácias. Na Avenida Almirante Barroso, seis estabelecimentos em oito quarteirões. Por se tratar de vias importantes, espera-se que haja fiscalização e maior atenção aos estabelecimentos que ali se encontram (considerando sua visibilidade). Porém observa-se que em ambas há presença maciça e agrupada de pontos com a ocorrência de infrações de diferentes tipos. A via Almirante Barroso está diretamente ligada às vias mais importantes da região metropolitana. Outro fator de debate é que a conformação da cidade de Belém nestes locais é de pontos onde a maioria dos imóveis é de comércio, logo, isto cria uma lógica espacial focada nesta atividade, o que reúne vários estabelecimentos de diversas naturezas ao longo de uma via ou em um mesmo local. Ao mesmo tempo em que isto amplia as opções do consumidor, lhe tira a capacidade de frequentar um local que vigia as normas da NBCAL, já que em quase todos os locais foi observada uma infração.

\section{Discussão}

O panorama que estamos discutindo neste trabalho envolve dinâmicas variadas e relaciona várias abordagens que perpassam um mesmo problema. Por si só a NBCAL é um instrumento regulatório que tem impacto sobre o marketing e o 
mercado, os desdobramentos deste estudo permitem enxergar os seus resultados a partir da ótica da postura da indústria farmacêutica, seus impactos na saúde pública e suas formas de utilização do espaço.

Para Costa et al. (2011), o aumento do uso terapia medicamentosa pela população é justificada pelo aumento do interesse por diferentes drogas (sentido de medicamento) em diferentes níveis sociais, a criação de políticas públicas que expandiram o acesso ao medicamento e a complexidade do mercado farmacêutico. De acordo com o Banco Nacional de Desenvolvimento Econômico e Social (BNDES, 2001), em 2001 existiam um pouco mais de 50 mil farmácias no país. As farmácias e drogarias constituem-se o principal canal de distribuição de medicamentos para a população brasileira, podendo, daí, verificar-se a importância desse segmento para o país, com movimento em torno de US\$ 8 bilhões anuais, resultado que coloca o Brasil, no cenário mundial, como o $8^{\circ}$ mercado de medicamentos, onde cerca de $80 \%$ dos negócios do setor referem-se à venda de medicamentos. Existiam no Brasil em 2001, um universo de pouco mais de 50 mil farmácias (país com o maior número de farmácias em todo o mundo), com uma proporção de 3,34 farmácias para cada 10 mil habitantes, considerando uma população de, aproximadamente, 167 milhões de habitantes. (BNDES, 2001) Atualmente, estima-se um número muito maior de farmácias e uma movimentação monetária proporcionalmente aumentada. Na mesma publicação citada acima, os autores sugerem que uma das apostas para melhorar o mercado do segmento é a diversificação dos produtos (BNDES, 2001). A Federação Brasileira de Farmácias (FEBRAFAR, 2019) afirma que o setor demonstrou crescimento expressivo do ramo, que se desenvolveu acima da média nacional. Segundo a mesma, o faturamento de 2018, até o mês de novembro foi 11,89\% maior que o período anterior, saltando de $\mathrm{R} \$ 106.800 .829 .321,00$ para $\mathrm{R} \$ 119.494 .748 .613,00$. A expansão desse mercado pode ter afetado as atividades de marketing praticadas pelas lojas, não só da venda de medicamentos, como dos outros artigos que são vendidos.

Os dados do monitoramento atual guardam relação com os demais já realizados e não evidenciam nenhuma mudança intensa no padrão de falta de cumprimento da NBCAL. O monitoramento 2014 já tinha demonstrado 95,6\% considerando todos os estabelecimentos pesquisados com amostras de várias cidades no Brasil. O tipo de infração desta comparação é da mesma natureza: comércio, promoção e publicidade, demonstrando uma redução, mas ainda uma imensa quantidade de irregularidades encontradas. O monitoramento da NBCAL realizado por Silva et al. (2020) utilizando os mesmos critérios, de nossa pesquisa, avaliou 352 estabelecimentos comerciais, dos quais 240 eram farmácias, $88 \%$ de todos os estabelecimentos comercializavam produtos em que é proibida a promoção comercial. Das promoções comerciais ilegais, os descontos em produtos proibidos pela NBCAL foram mais frequentes $(13,2 \%)$. Exposições especiais somaram 9,3\%. Para os autores, mais de um quinto dos estabelecimentos pesquisados na zona sul do Rio de Janeiro realizaram promoções irregulares em alimentos infantis e outros produtos, como bicos e chupetas (Silva et al., 2020). Já em Curitiba, um monitoramento com 31 estabelecimentos, apresentou pelo menos metade do número (48\%) com inadequações (Almeida et al., 2020). As atividades de venda de produtos em uma farmácia dependem de legislação própria e são regulados por órgãos municipais. Na cidade de Belém, a DIVISÃO DE VIGILÂNCIA SANITÁRIA DE DROGAS E MEDICAMENTOS é a responsável pela emissão de licença de funcionamento dos estabelecimentos e deve fiscalizar frequentemente e sem aviso prévio, o cumprimento das legislações que se aplicam ao local e às práticas (Prefeitura De Belém, 2021). Muito embora se disponha de diversos dispositivos legais que legitimem a fiscalização e o acompanhamento das atividades destes estabelecimentos, a presença dos números de infrações elevados, demostra que existe uma deficiência no cumprimento da NBCAL. Boccolini et al. (2020) enquanto discutiram os instrumentos de pesquisa utilizados neste e em outros monitoramentos descreveram que a pesquisa nacional, que contou com 1487 amostras, apresentou mais de $60 \%$ de ilegalidades. Durante a pesquisa, uma das perguntas do roteiro de entrevista com o responsável questionava a quem competia à organização dos produtos e a disposição dos mesmos no salão da loja. Em todos os estabelecimentos pertencentes a redes, a responsabilidade provinha de um setor específico de leiaute. Nas farmácias com infração, ficou aparente que o profissional responsável não cumpriu a NBCAL no que tange às restrições que a lei impõe, como a exposição especial de certos produtos.

Como já descrito, o comércio de medicamentos também tem se fortalecido nos últimos anos, resultado de uma saúde pública tomada pela força do capitalismo e de perfis neoliberais que se aplicam à terapêutica, mesmo em um país que possui um 
serviço de saúde universal, de cobertura integral e unificada. A cidade pesquisada tem em seu escopo comercial, a presença forte de grupos de drogarias, onde são vendidos diversos tipos de produtos, não se limitando apenas ao comércio de medicamentos e afins.

Cleps (2004) explica que o espaço onde o comércio se reproduz é estratégico do ponto de vista mercadológico, uma vez que se utiliza das vias mais movimentadas e por onde se tem um maior trânsito de pessoas. A autora ainda incorpora o papel social do comércio enquanto capaz de interagir com o espaço geográfico, para seu benefício e até mesmo modificá-lo para valorizar financeiramente uma determinada área. Os novos tipos de transportes, à comunicação à distância, a propaganda, a concentração de informações, as novas técnicas monetárias, a busca de conveniência, a interação entre consumo de alimentos e meio ambiente, a valorização da saúde, da vitalidade e da individualidade são elementos que fazem parte do processo produtivo atual e criam novos espaços de produção, circulação, distribuição e consumo (Cleps, 2004). Embora não tenhamos identificado o IDH de cada bairro citado na pesquisa, a dinâmica da cidade de Belém, como muitas das cidades brasileiras, tem uma concentração de renda e riqueza maior nos bairros centrais, como evidenciam Vieira et al. (2018). Traça-se assim um perfil econômico que pode ser comparado tanto com a concentração maior de estabelecimentos nos bairros mais ricos como a presença maior de infrações.

Neste trabalho foi verificado o espalhamento maior dos pontos sem infração. Todos os pontos sem infração da região central não são mais numerosos que os demais, de regiões mais distantes, isso significa que embora possa haver um viés matemático pela quantidade maior do número de estabelecimentos nas áreas mais "nobres", o argumento não é suportado pela avaliação da quantidade de pontos sem infração. Corroborando estas informações, Vieira et al. (2018), expressaram graficamente a concentração de renda de chefes de família no mesmo espaço analisado por esta pesquisa, utilizando metadados do IBGE de 2010. Ficou claro que a maior concentração de riquezas (expressada em ganho salarial) esteve presente principalmente nas regiões centrais da cidade, onde houve maiores ocorrências de infrações. Expressando os extremos da pesquisa, as figuras à representam graficamente a concentração de chefes de família que recebem até 0,5 salários mínimos e entre cinco e 10 salários mínimos respectivamente.

Figura 4. Chefes de família com rendimento nominal mensal até 1⁄2 salários mínimos, Belém - Pará, 2010.

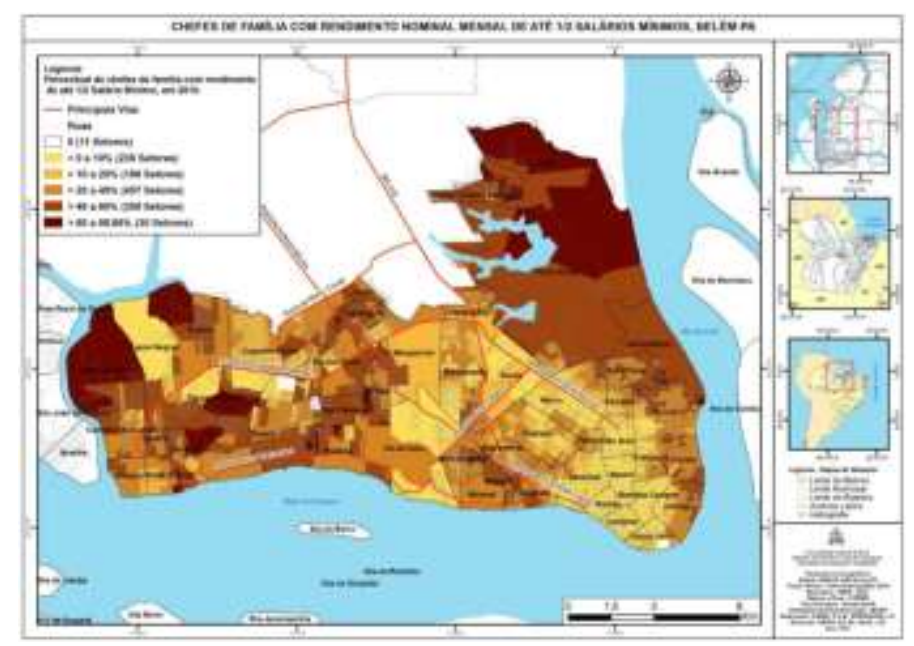

Fonte: Vieira et al. (2018). 
Figura 5 - Chefes de família com rendimento nominal mensal de 5 a 10 salários mínimos, Belém - Pará, 2010.

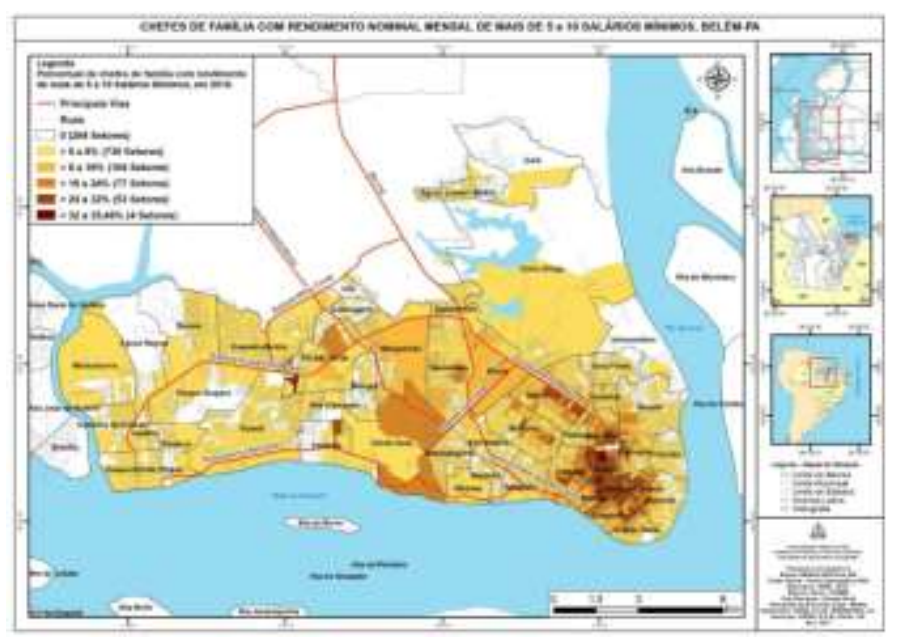

Fonte: Vieira et al. (2018).

De um ponto de vista 'macro' mas, ainda no contexto geográfico, as taxa de amamentação têm uma forte relação com a faixa de renda dos países. No ano de 2018, o UNICEF apresentou relatório, fruto de estudos em mais de 120 países, onde concluíram que os países mais ricos, tem uma menor taxa de amamentação, consequentemente os países de baixa e média renda acabam sendo mais eficientes na prática da amamentação. Dentre os fatores que impactam estão o incentivo governamental e a legislação do marketing de alimentos (UNICEF, 2018). Nos países mais ricos, mais que um em cada cinco bebês nunca foram amamentados, nos países de média e baixa renda, quase todos os bebês foram amamentados ao menos uma vez (UNICEF, 2018).

\section{Conclusão}

Por meio desta pesquisa, que reuniu resultados da avaliação do cumprimento da NBCAL e a distribuição espacial das infrações, bem como sua concentração em ambientes mais ricos, é possível afirmar que ainda existe um déficit, tanto na fiscalização quanto no acompanhamento das atividades de mercado de alimentos e produtos para lactentes. Estas não conformidades aumentam o risco de exposição do recém-nascido a não ser amamentado em momento algum, não ser amamentado exclusivamente até os sies meses, não ser amamentado até os dois anos, ter contato com leite de vaca antes dos 12 meses de vida, fazer uso de bicos, chupetas e mamadeiras e substituir alimentos in natura por cereais e papinhas depois dos seis meses.

Para modificar o cenário, algumas ações podem ser adotadas e devem guiar políticas públicas governamentais. Para o UNICEF e o IBFAN, as políticas necessárias giram em alguns eixos principais: As políticas governamentais de gerenciamento, que envolvem o cumprimento do Código internacional de comercialização de substitutos do leite materno (no Brasil representado pela NBCAL) e outras políticas, a existência de programas de monitorização e a qualificação de profissionais. O outro eixo de ações parte do empoderamento de mães e práticas clínicas que priorizem a amamentação.

Em resumo, políticas governamentais, empoderamento feminino, democratização de conhecimento a toda sociedade e fiscalização adequada de estabelecimentos refletem as principais ações norteadoras para fortalecer a prática adequada da amamentação, uma vez que os principais problemas encontrados durante este levantamento podem ser sanados através destas atitudes. Ainda existem muitas falhas no movimento regulatório do marketing de alimentos para crianças, mas é notável uma evolução neste quesito, a despeito dos esforços da indústria de alimentos. Novas demandas surgem e sugerem desafios para entidades de proteção ao direito das crianças e profissionais de saúde pública.

É fundamental a manutenção dos monitoramentos realizados pela rede IBFAN (Rede Internacional em Defesa do Direito de Amamentar) e necessário que se realizem estudos voltados para a investigação dos impactos do não cumprimento destas legislações em todos os estados do Brasil. 


\section{Referências}

Almeida, C. L., Ribeirto, A. P. \& Thieme, R. D. (2020). Inconformidades à norma brasileira de comercialização de alimentos para lactentes em estabelecimentos comerciais de Curitiba, PR. Anais do Segundo Congresso De Saúde Coletiva Da UFPR. UFPR. https://eventos.ufpr.br/csc/csc20/paper/view/4160

Banco Nacional de Desenvolvimento Econômico e Social. (2001). Um panorama do varejo de farmácias e drogarias no Brasil. https://www.bndes.gov.br/SiteBNDES/export/sites/default/bndes_pt/Galerias/Arquivos/conhecimento/setorial/get4is25.pdf

Barbosa, D. J., Vasconcelos, T. C. \& Gomes, M. P. (2020). Fatores que interferem no aleitamento materno exclusivo durante os primeiros seis meses de vida do bebê. Revista Pró-UniverSUS, 11(1) 80-87. http://editora.universidadedevassouras.edu.br/index.php/RPU/article/view/2208

Boccolini, C., Boccolini, P. \& Mezzavilla, R. (2020). National System to Monitor the International Code of Breast Milk Substitutes in Brazil: SisNBCAL, Current Developments in Nutrition, 4 (2), 705 https://doi.org/10.1093/cdn/nzaa051_002

Braga, M. S., Gonçalves, M. S. \& Augusto, C. R. (2020). Os benefícios do aleitamento materno para o desenvolvimento infantil. Brazilian Journal of Development, 6(9), 70250-70261. https://doi.org/10.34117/bjdv6n9-468

Cleps, G. D. G. (2004). O comércio e a cidade: novas territorialidades urbanas. Revista Sociedade \& Natureza, 16(30). http://www.seer.ufu.br/index.php/sociedadenatureza/issue/view/534

Costa, K. S., Barros, M. B. A., Francisco, P. M. S. B., César, C. L. G., Goldbaum, M. \& Carandina, L. (2011). Utilização de medicamentos e fatores associados: um estudo de base populacional no Município de Campinas, São Paulo, Brasil. Cad. Saúde Públic, 27(4), 649-658. https://doi.org/10.1590/S0102311 X2011000400004

Federação Brasileira de Farmácias. Mercado farmacêutico. (2019). https://www.febrafar.com.br/mercado-farmaceutico-2019-veja-expectativas/

Gradim, C. V. C., Magalhães, M. C., Faria, M. C. F. \& Arantes, C. I. S. (2011). Aleitamento materno como fator de proteção para o câncer de mama. Rev Rene, 12(2), 358-64. http://periodicos.ufc.br/rene/article/view/4220/3260

Instituto De Defesa Do Consumidor. Amamentação desvalorizada. Revista do Idec. 195, 22.

International Baby Food Action Network Brasil. (2007). Rede Internacional em Defesa do Direito de Amamentar. Alimentos para crianças de até 3 anos, bicos, chupetas e mamadeiras. O que você precisa saber! http://www.ibfan.org.br/parceiros/pdf/2.pdf

International Baby Food Action Network Brasil. (2008). Rede Internacional em Defesa do Direito de Amamentar. Relatório nacional das violações à Norma Brasileira de Comercialização de Alimentos para Lactentes e Crianças de Primeira Infância, Bicos, Chupetas e Mamadeiras e Lei 11.265/2006. 1.

Machado, P. P., Oliveira, N. R. F. \& Mendes, A. N. (2016). O indigesto sistema do alimento mercadoria. Saúde e Sociedade, 25(2), 505- 515. https://doi.org/10.1590/S0104-12902016151741

Pereira-Santos, M., Santana, M. S., Oliveira, D. S., Nepomuceno Filho, R. A., Lisboa, C. S., Almeida, L. M. R., Gomes, D. R., Queiroz, V. A. O., Demétrio, F. \& Oliveira, A. M. (2017). Prevalência e fatores associados à interrupção precoce do aleitamento materno exclusivo: metanálise de estudos epidemiológicos brasileiros. Rev. Bras. Saude Mater. Infant. 17(1), 59-67. https://doi.org/10.1590/1806-93042017000100004

Prefeitura De Belém. Vigilância Sanitária. 2021. https://sesma.belem.pa.gov.br/atendimento/vigilancia-sanitaria

Rochelle, I. M. F., Tagliaferro, E. P. S., Pereira, A. C., Meneghim, M. C., Nóbilo, K. A. \& Ambrosano, G. M. B. (2010). Amamentação, hábitos bucais deletérios e oclusopatias em crianças de cinco anos de idade em São Pedro, SP. Dental Press J. Orthod. 15(2) https://doi.org/10.1590/S2176-94512010000200010

Santana, J. V. \& Holanda, A. C. G. (2012). Reflexões acerca da carência habitacional no Pará: dados comparativos entre os anos 2000 e 2010 . In Gomes, V. L. B., Vieira, A. C. S., \& Nascimento, M. A. C. (Org.) O avesso dos direitos: Amazônia e Nordeste em questão. Recife: Editora Universitária Ufpe. 271-307. https://editora.ufpe.br/books/catalog/book/112

Silva, K. B., Oliveira, M. I. C., Boccolini, C. S. \& Sally, E. O. F. (2020). Illegal commercial promotion of products competing with breastfeeding. Rev. Saúde Pública. 54, 10 .

United Nations Children's Fund. (2016). Unicef global databases, based on MICS, DHS and other nationally representative sources. http://data.unicef.org/nutrition/iycf.html\#sthash.nEsKwT3U.dpuf.

United Nations Children's Fund. (2018). Breasstfeeding: A Mother's Gift, for Every Child. https://data.unicef.org/resources/breastfeeding-a-mothers-gift-forevery-child/

Victora, C. G., Bahl, R., Barros, A. J., França, G. V., Horton, S., Krasevec, J., Murch, S., Sankar, M. J., Walker, N., Rollins, N. C. \& Lancet Breastfeeding Series Group. (2016). Breastfeeding in the 21st century: epidemiology, mechanisms, and lifelong effect. The Lancet, 387, 475-490 https://doi.org/10.1016/S01406736(15)01024-7

Vieira, D. C. M., Rodrigues, J. C. \& Rodrigues, J. C. (2017). Mapeamento e análise das desigualdades socioespaciais: abordagem interpretativa da cidade de Belém, Pará. Geosaberes, 9(17), 1-21. https://doi.org/10.26895/geosaberes.v9i17.612

World Health Organization. (2008). Indicators for assessing infant and young child feeding practices: part 1: definitions: conclusions of a consensus meeting held 6-8 November 2007 in Washington DC, USA. https://apps.who.int/nutrition/publications/infantfeeding/9789241596664/en/index.html

World Health Organization. (2014). Global nutrition targets 2025: wasting policy brief. https://apps.who.int/iris/handle/10665/149023 